\title{
DIETETIC TREATMENT OF CHRONIC ARTHRITIS AND ITS RELATIONSHIP TO THE SUGAR TOLERANCE *
}

\author{
A. ALMON FLETCHER, M.B. \\ TORONTO
}

The importance of diet in the treatment of chronic arthritis is a question on which there is today considerable difference of opinion. In practice, its effect, as a rule, is confused by the establishment of several forms of treatment at one time, such as the removal of infectious foci, rest in bed, electrotherapy and hydrotherapy and other hygienic measures. It is, however, the experience of many observers that improvement is often brought about by changes in diet alone. But as to the character of this change, difference of opinion also exists. Increase in diet is recommended by some and decrease by others, or reduction of proteins in one case and reduction of carbohydrates in another. Sometimes improvement has been so marked as to lead older clinicians to believe that the disease had a metabolic basis, but clinical and laboratory investigation has not offered much evidence to support this hypothesis. In fact, interest has been more directed toward the part played by bacteria in the causation of this disease, and recent work has resulted in the general belief that chronic arthritis-with the exception of those cases due to trauma, strain, gout, some neuropathy, scurvy and hemophilia-is the result of a bacterial process. It is, therefore, natural that the origin of such infection should be looked for, infectious foci removed, vaccines administered, and, if necessary, some form of nonspecific protein therapy utilized. These measures are often attended by marked success, but sometimes results are disappointing, and if improvement occurs, it is often of a temporary nature.

In spite of this belief that the condition is a bacterial disease, there are still clinicians who insist on the importance of diet in its treatment. Pemberton, ${ }^{1}$ especially, has for many years advised careful dietetic regulation-recommending a general reduction of the food intake, and laying special stress on the restriction of carbohydrates. In our own clinic, we have been impressed with the value of this recommendation in many cases. And, further, in those cases which receive benefit from such treatment, there has been as much clinical evidence of infection as in those which are refractory to such measures. One case, in which

\footnotetext{
* From the Department of Medicine. University of Toronto, and from the Medical Division of the Toronto General Hospital.

1. Pemberton, R.: Use of Diet in Treatment of Chronic Arthritis, Am. J. M. Sc. 161:517 (Apri1) 1921.
} 
a hemolytic streptococcus was isolated from the blood during the height of the arthritis, showed prompt and quite marked improvement with a sudden reduction of diet. This reduction was made about six weeks after the onset of the attack, while the patient was still in a febrile state, and the favorable course of the infection was undoubtedly brought about by the change in diet. It would seem, then, that in such cases, there is a relationship between the maintenance of an infection and an unsuitability of the diet to the patient. This unsuitability might be due either to actual lack of balance in selection of food or to some error in the metabolism of the patient.

In a metabolic study of chronic arthritis, Pemberton and Foster ${ }^{2}$ observed that the rise in blood sugar, following the administration of $100 \mathrm{gm}$. glucose, was both increased and prolonged. They further concluded that this lowering of sugar tolerance was roughly an indication of the severity of the disease-tending to return to normal as convalescence set in. If this were the case, a determination of sugar tolerance would not give any specific information bearing on a case, other than its severity, but our own figures were not in accord with this conclusion, for it was sometimes found that some of the mildest cases showed a well-marked decrease in the sugar tolerance, which might even persist after recovery, while cases of the severest type sometimes gave figures which varied but slightly from normal. This question then presented itself: Does the lowering of sugar tolerance call for reduction of diet, and is the degree to which this tolerance is lowered any indication of the probability of giving relief by such measures? With this question in mind, we present the records of 100 cases of chronic arthritis in which the sugar tolerance was determined and in which the effect of reduction of diet alone was studied.

Method of Treatment.-The 100 cases represent a selection from 160 cases of nonpurulent arthritis admitted to the medical wards of the Toronto General Hospital, and a few cases seen outside. The remaining sixty cases could not be included for various reasons. Many patients recovered without special treatment; a few recovered after removal of some focus of infection; others left the hospital before treatment was adequately observed. The cases associated with gonococcal infections are not included. Following McCrae's ${ }^{3}$ classification, the majority of cases were of the periarticular type, with or without deformity; a few showed hypertrophic bone changes, and one or two cases showed both types of the disease. The duration of the condition is shown in the tables, and in no case was dietetic treatment started before six weeks after the onset. The patients who were

2. Pemberton, R., and Foster, G. L.: Arch. Int. Med. 25:243 (March) 1920.

3. McCrae: Oxford Med. 4:374, 1921. 
admitted to hospital were allowed to remain in bed for two weeks at least, and until the process appeared to have reached a more or less stationary stage. This was done because rest alone may result in considerable improvement or even recovery. A few patients were treated outside of hospital, and in these no changes were made in the manner of living, other than the change in diet.

Dietetic treatment was carried out as far as possible in a routine manner, without regard for the patient's tolerance for carbohydrates or for his former diet. At first various changes in diet were tried. Reduction of the carbohydrates to one fifth or less of the usual intake sometimes was followed by much improvement. But better results were obtained by a more general reduction, and the large majority of the 100 patients were treated in the following manner: three glasses of milk, 3 glasses of buttermilk, one-half grape fruit and one or two oranges a day for one week; then the gradual addition of such food as eggs, fish, fowl, meat, 5, 10 and 15 per cent. vegetables, fruits, junkets and jellies; and finally, brown bread in small amounts. Patients who were underweight were allowed cod liver oil and cream. This increase was made so as to provide from 1,500 to 2,000 calories a day within four weeks' time. The improvement noted in the tables occurred within this period, and with one or two exceptions, if no progress had been observed, it was not found worth while to continue. But those who did well were recommended to adhere to the diet-many reported progress for several months, and a few found that a relapse set in if their former diet was indulged in too freely.

While the effect of this treatment was being observed, no other form of treatment was given. If foci of infection were removed, four weeks were allowed to pass, but often these foci were untouched until after the period of observation. No drug was given, and physiotherapy was not ordered. When necessary, the bowels were moved on alternate days by enemas, and in a few cases liquid petrolatum was given by mouth.

The Sugar Tolerance.-The test was carried out as recommended by Hamman and Hirschman. ${ }^{4}$ After a fast of fifteen hours, $100 \mathrm{gm}$. glucose was given by mouth in 300 c.c. of water, with the addition of the juice of half a lemon; 250 c.c. of water was given at one and two hour intervals. Blood sugar determinations were made immediately before the administration of the sugar and one-half hour, one hour, two hours and three hours afterward. The half-hour determination did not appear to give any essential information in most cases, and was discontinued. In a few cases, it was convenient to obtain blood at one

4. Hamman, L., and Hirschman, F. I.: Alimentary Hyperglycemia and Glycousuria as a Test for Sugar Tolerence, Arch. Int. Med. 20:761 (Nov.) 1917. 
and one-half hour intervals only-these two determinations being usually sufficent to establish the existence of definite lowering of the tolerance. All the determinations were done by the method of Folin and $\mathrm{Wu},{ }^{5}$ the blood, as a rule, being precipitated at the bedside and the colorimetric reading done the same day; the figures are given in mg. per c.c.

For the interpretation of the blood sugar readings, after the ingestion of $100 \mathrm{gm}$. glucose, it appears that three aspects are to be considered: (1) the maximum figure obtained; (2) the time at which the maximum occurs, and (3) the time required for the return to normal. There is still some disparity as to what should be considered a normal reaction. In our own work, a figure above 1.7 or a failure to return to the original level in ninety minutes, has been taken as a disturbance in sugar tolerance. In health, the maximum is reached in less than sixty minutes. In many of the figures presented, the maximum occurred later than this, but as this point possibly was frequently missed, it cannot be considered specially. The striking characteristic of the figures presented is the height which many of the figures reached, and especially the delay in the return. This last point is well brought out by the method of determining the blood sugar at one hour or one hour and a half intervals. For purposes of comparison, an average was taken of the figures obtained after the administration of the glucose, either at the hour or at one hour and a half intervals. These averages take into account both the maximum reached and the delay in the return, and in the tables the cases are grouped according to these averages. Three arbitrary groups were selected: (1) those in which the average was less than 1.4 ; (2) those in which the average was from 1.4 to 2 , and (3) those in which the average was greater than 2 .

Table 1 shows that the figures obtained varied from those which fell within normal limits to those which might be considered as indicating frank diabetes. And, indeed, no line can be drawn so as to classify the cases into diabetics and nondiabetics. Of the 100 cases, twenty-four belonged to Group I; i. e., with the average of the figures obtained under 1.4; fifty-six belonged to Group II, with an average of from 1.4 to 2 , and twenty belonged to Group III, with an average greater than 2 .

As to the relationship of the sugar tolerance to the severity of the disease, none was found; as many mild cases were found to appear in the group with the low tolerance as in the group with the high tolerance; of the twenty most severe cases, six belonged to Group I, ten to

5. Folin. O., and Wu, H.: System of Blood Analysis; a Simplified and Improved Method for Determination of Sugar, J. Biol. Chem. 41:367, 1920. 
Table 1.-Cases in Which the Blood Sugar Averaged Less Than 1.4 Mg. per C.c. for Three Hours After Administration of 100 Gm. Glucose

\begin{tabular}{|c|c|c|c|c|c|c|c|c|c|c|c|}
\hline Case & Sex & Age & $\begin{array}{l}\text { Dura- } \\
\text { tjon } \\
\text { Before } \\
\text { Admis- } \\
\text { sion }\end{array}$ & $\begin{array}{l}\text { Fast- } \\
\text { ing } \\
\text { Blood } \\
\text { Sugar }\end{array}$ & $\begin{array}{c}1 / 2 \\
\text { Hour }\end{array}$ & $\stackrel{1}{\text { Hour }}$ & $\begin{array}{c}11 / 2 \\
\text { Hours }\end{array}$ & $\stackrel{2}{\text { Hours }}$ & $\stackrel{3}{\text { Hours }}$ & $\begin{array}{l}\text { Aver- } \\
\text { age }\end{array}$ & $\begin{array}{l}\text { Result of } \\
\text { Treatment }\end{array}$ \\
\hline $\begin{array}{r}1 \\
2 \\
3 \\
4 \\
5 \\
6 \\
7 \\
8 \\
9 \\
10 \\
11 \\
12 \\
13 \\
14 \\
15 \\
16 \\
17 \\
18 \\
19 \\
20 \\
21 \\
22 \\
23 \\
24\end{array}$ & $\begin{array}{l}\mathbf{M} \\
\mathbf{F} \\
\mathbf{F} \\
\mathbf{M} \\
\mathbf{M} \\
\mathbf{M} \\
\mathbf{M} \\
\mathbf{F} \\
\mathbf{F} \\
\mathbf{F} \\
\mathbf{M} \\
\mathbf{M} \\
\mathbf{F} \\
\mathbf{F} \\
\mathbf{F} \\
\mathbf{M} \\
\mathbf{M} \\
\mathbf{M} \\
\mathbf{M} \\
\mathbf{M} \\
\mathbf{M} \\
\mathbf{M} \\
\mathbf{M} \\
\mathbf{F}\end{array}$ & $\begin{array}{l}23 \\
30 \\
39 \\
38 \\
29 \\
38 \\
26 \\
20 \\
31 \\
63 \\
32 \\
56 \\
55 \\
61 \\
56 \\
27 \\
34 \\
33 \\
30 \\
26 \\
65 \\
40 \\
60 \\
33\end{array}$ & 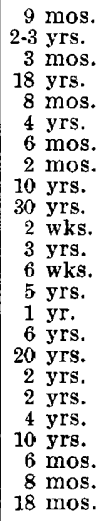 & $\begin{array}{l}0.86 \\
1.06 \\
0.82 \\
0.98 \\
1.05 \\
0.84 \\
0.99 \\
1.11 \\
1.15 \\
1.09 \\
0.99 \\
0.93 \\
1.28 \\
1.05 \\
1.25 \\
1.26 \\
0.93 \\
1.10 \\
0.91 \\
0.95 \\
1.21 \\
1.25 \\
1.00 \\
1.12\end{array}$ & $\begin{array}{l}\ldots \\
\ldots \\
\ldots \\
\ldots \\
1.67 \\
1.34 \\
1.47 \\
\ldots . \\
\ldots \\
\ldots \\
\ldots \\
\ldots \\
\ldots \\
\ldots \\
\ldots \\
\ldots \\
\ldots \\
\ldots \\
\ldots \\
\ldots \\
\ldots \\
\ldots\end{array}$ & $\begin{array}{l}1.25 \\
1.18 \\
0.93 \\
1.37 \\
1.73 \\
1.49 \\
1.58 \\
\ldots .7 \\
1.51 \\
1.55 \\
1.87 \\
1.63 \\
\ldots \ldots \\
1.70 \\
1.30 \\
1.75 \\
1.39 \\
1.33 \\
1.34 \\
1.33 \\
\ldots .7 \\
1.74 \\
1.27 \\
\ldots . .\end{array}$ & 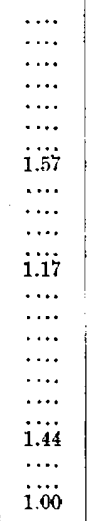 & $\begin{array}{l}1.21 \\
1.17 \\
1.30 \\
1.45 \\
1.07 \\
1.29 \\
1.44 \\
\ldots .75 \\
1.20 \\
1.02 \\
1.73 \\
\ldots .11 \\
1.110 \\
0.95 \\
1.46 \\
0.94 \\
0.69 \\
0.75 \\
\ldots .32 \\
1.32 \\
1.06 \\
\ldots . .\end{array}$ & $\begin{array}{l}1.03 \\
105 \\
1.10 \\
1.36 \\
1.16 \\
1.23 \\
0.71 \\
0.94 \\
1.19 \\
0.94 \\
1.16 \\
0.66 \\
1.19 \\
0.90 \\
1.05 \\
0.79 \\
1.21 \\
0.74 \\
0.67 \\
0.77 \\
0.91 \\
1.11 \\
1.24 \\
0.80\end{array}$ & $\begin{array}{l}1.16 \\
1.13 \\
1.11 \\
1.39 \\
1.32 \\
1.39 \\
1.24 \\
1.25 \\
1.15 \\
1.23 \\
1.35 \\
1.37 \\
1.18 \\
1.23 \\
1.34 \\
1.16 \\
1.65 \\
1.01 \\
0.90 \\
0.95 \\
1.17 \\
1.39 \\
1.19 \\
0.9\end{array}$ & $\begin{array}{l}\text { Improved } \\
\text { Improved } \\
\text { No improvement } \\
\text { Improved } \\
\text { No improvement } \\
\text { Improved } \\
\text { No improvement } \\
\text { Recovered } \\
\text { Improved } \\
\text { No improvement } \\
\text { Improved } \\
\text { Improved } \\
\text { Improved } \\
\text { Improved } \\
\text { Much improved } \\
\text { No improvement } \\
\text { No improvement } \\
\text { No improvernent } \\
\text { No improvement } \\
\text { No improvement } \\
\text { No improvement } \\
\text { Improved } \\
\text { No improvement } \\
\text { Much improved }\end{array}$ \\
\hline
\end{tabular}

Cases in which the Average was 1.4-2 Mg. Per C.c.

\begin{tabular}{|c|c|c|c|c|c|c|c|c|c|c|c|}
\hline 25 & $\mathbf{F}$ & 29 & 10 yrs. & 1.2 & & 1.8 & $\ldots$ & 1.7 & 1.5 & 1.6 & Much improved \\
\hline 26 & $\mathbf{F}$ & 38 & 4 yrs. & 1.3 & .... & 1.7 & $\ldots$ & 1. & 1.3 & 1.6 & Much improved \\
\hline 27 & $\mathbf{F}$ & 38 & $11 / 2$ yrs. & 1.1 & $\ldots$ & 1.3 & $\ldots$ & 1. & 1.75 & 1.61 & Much improved \\
\hline 28 & $\mathbf{M}$ & 20 & 8 wks. & 1.1 & & 1.5 & $\ldots$ & 1. & 1.3 & 1.42 & Much improved \\
\hline 29 & $\mathbf{F}$ & 37 & 2 yrs. & 1.08 & 1.17 & 2.04 & $\ldots$ & 1.99 & 1.05 & 1.69 & No improvenent \\
\hline 30 & $\mathbf{F}$ & 35 & 3 mos. & 1.12 & 1.63 & 2,12 & $\ldots$ & 2.17 & 1.37 & 1.88 & Much improved \\
\hline 31 & $\mathbf{M}$ & 40 & 3 yrs. & 0.97 & 1.56 & 1.82 & $\ldots$ & 2.54 & 1.55 & 1.97 & Improved \\
\hline 32 & $F$ & 32 & 1 yr. & 0.94 & 1.69 & 2.22 & $\ldots$ & 1.97 & 0.63 & $1.6 ?$ & Much improved \\
\hline 33 & $\mathbf{M}$ & 54 & 7 wks. & 1.09 & 1.83 & 2.31 & & 1.85 & 1.75 & 1.97 & Mueh improved \\
\hline 34 & $\mathbf{F}$ & 34 & 3 yrs. & 1.05 & $\ldots$ & $\ldots$ & 2.10 & $\ldots$ & 1.60 & 1.85 & Improved \\
\hline 35 & $\mathbf{F}$ & 39 & $2 \mathrm{mos}$. & 1.07 & & & 1.45 & & 1.46 & 1.45 & Much improved \\
\hline 36 & $\mathrm{M}$ & 17 & $2 \mathrm{mos}$. & 1.12 & 1.47 & 1.87 & $\ldots$ & 1.71 & 1.44 & 1.67 & Much improved \\
\hline 37 & $\mathbf{F}$ & 28 & $6 \mathrm{wks}$. & 1.04 & $\ldots$ & & 1.73 & & 3.4 & 153 & Recovered \\
\hline 38 & $\mathbf{F}$ & 48 & 20 yrs. & 0.87 & $\ldots$ & 1.52 & $\ldots$ & 1.67 & 1.19 & 1.46 & Jmproved \\
\hline 39 & $\mathbf{F}$ & 60 & $1 \mathrm{yr}$. & 0.9 & $\ldots$ & 1.86 & $\ldots$ & 1.26 & 1.25 & 1.45 & Much improved \\
\hline 40 & $\mathbf{F}$ & 35 & 2 yrs. & 1.24 & $\ldots$ & 1.98 & $\ldots$ & 1.61 & 1.18 & 1.59 & Improved \\
\hline 41 & $\mathbf{F}$ & 24 & $1 \mathrm{yr}$. & 1.08 & .... & 1.58 & $\ldots$ & $1 . \overline{3}$ & 1.51 & $1, \overline{1} 4$ & No improvement \\
\hline 42 & $\mathbf{F}$ & 40 & 2 wks. & 0.88 & $\ldots$ & 1.62 & $\ldots$ & 1.91 & 1.64 & $i$. & Much jmproved \\
\hline 43 & $\mathbf{F}$ & 60 & 15 yrs. & 1.10 & .... & .... & 1.75 & & 1.44 & 1.59 & Improved \\
\hline 44 & $\mathbf{F}$ & 28 & 4 yrs. & 1.65 & $\ldots$ & 1.94 & $\ldots$ & 1.54 & 0.97 & 1.48 & Much improved \\
\hline 45 & $\mathbf{F}$ & 58 & 8 yrs. & 1.03 & $\ldots$ & 1.67 & $\ldots$ & 1.67 & 1.65 & 1. & Improved \\
\hline 46 & $\mathbf{M}$ & 23 & 7 yrs. & 1.10 . & $\ldots$ & 1.75 & $\ldots$ & 1.50 & 1.50 & 1.59 & Much improved \\
\hline 47 & $\mathbf{F}$ & 35 & 11 yrs. & 1.17 & $\cdots$ & 1.98 & $\ldots$ & 1.42 & 1.22 & 1.54 & Improved \\
\hline 48 & $\mathbf{M}$ & 35 & 1 yr. & 1.3 & .... & 2.0 & $\ldots$ & 1. & 1.4 & 1.6 & Much improved \\
\hline 49 & $F$ & 52 & 18 mos. & 1.08 & $\ldots$ & 2.50 & $\ldots$ & 1.90 & 0.90 & 1. & Much improved \\
\hline 50 & $\mathrm{~F}$ & 45 & 2 wks. & 0.95 & .... & 2.54 & $\ldots$ & 2.13 & 1.22 & 1.65 & Recovered \\
\hline 51 & $\mathbf{M}$ & 45 & 10 yrs. & 1.17 & $\ldots$ & 2.16 & & 1.87 & 0.94 & 1.65 & No improvemen \\
\hline 52 & $\mathbf{M}$ & 50 & 2 yrs. & 1.3 & $\ldots$ & 1.5 & $\ldots$ & 2. & 1.3 & 1.6 & Improved \\
\hline 53 & $\mathbf{F}$ & 29 & 6 wks. & 1.2 & $\ldots$ & 2.15 & $\ldots$ & 1.6 & 0.95 & 1.56 & ved \\
\hline 54 & $\mathrm{M}$ & 49 & 2 yrs. & 1.1 & $\ldots$ & 2.2 & $\ldots$ & 1.55 & 1. & 1. & oved \\
\hline 55 & $\mathbf{F}$ & 36 & 8 wks. & 1.3 & .... & 2 . & $\ldots$ & 1.5 & 1. & 1. & Much improved \\
\hline 56 & M & 47 & 9 mos. & 1.08 & .... & 2.20 & $\ldots$ & 1.68 & 1.85 & 1.91 & Much improved \\
\hline 57 & $\mathrm{~F}$ & 54 & ] $\mathrm{yr}$. & 1.13 & $\ldots$ & $\cdots$ & 2.27 & $\ldots$ & 1.33 & 1.80 & Much improved \\
\hline 58 & M & 57 & 8 yrs. & 1.12 & $\ldots$ & $\ldots$ & 2.07 & & 1.74 & ]. & No improvement \\
\hline 59 & $\mathrm{~F}$ & 34 & 5 wks. & 1.29 & $\cdots$ & 1.53 & $\ldots$ & 2.20 & 1.41 & 1.71 & Recovered \\
\hline 60 & $\hat{\mathbf{M}}$ & 42 & $1 \mathrm{yr}$. & 1.13 & $\ldots$ & 2.00 & $\ldots$ & 1.47 & 0.95 & 1.47 & Much improved \\
\hline 61 & $\mathbf{M}$ & 30 & 5 yrs. & 1.2 & $\ldots$ & 2.08 & & 2.08 & 1.34 & 1. & Much improved \\
\hline 69 & $\mathbf{M}$ & 47 & t wks. & 1.0 & .... & 2.20 & $\ldots$ & 1.68 & 1.85 & 1.91 & Much improved \\
\hline 63 & $\mathbf{F}$ & 35 & $1 \mathrm{yr}$. & 2.18 & $\ldots$ & 2.20 & $\ldots$ & 1.98 & 1.38 & 1.85 & Improved \\
\hline 64 & $\mathbf{F}$ & 20 & $1 \mathrm{yr}$. & 1.18 & $\ldots$ & 2.41 & $\ldots$ & 1.92 & 1.29 & 1.87 & Improved \\
\hline 65 & $\mathrm{~F}$ & 26 & $8 \mathrm{mos}$ & 1.07 & $\ldots$ & 2.42 & & 1.98 & 1.36 & 1.92 & Improved \\
\hline 66 & $\mathbf{F}$ & 22 & $6 \mathrm{wks}$. & 1.00 & $\ldots$ & 2.00 & $\ldots$ & 3.10 & 1.40 & 1.83 & Recovered \\
\hline 67 & $\mathbf{F}$ & 43 & 6 mos. & 1.2 & $\cdots$ & 2.2 & $\cdots$ & 1.85 & $0 . \hbar^{\circ}$ & i.t 0 & No improvement \\
\hline
\end{tabular}


Table 1 (Continued).-Cases in which the Average was 1.4-2 Mg. Per C.c.

\begin{tabular}{|c|c|c|c|c|c|c|c|c|c|c|c|}
\hline Case & Sex & Age & $\begin{array}{l}\text { Dura- } \\
\text { tion } \\
\text { Before } \\
\text { Admis- } \\
\text { sion }\end{array}$ & $\begin{array}{l}\text { Fast- } \\
\text { ing } \\
\text { Blood } \\
\text { Sugar }\end{array}$ & $\begin{array}{c}1 / 2 \\
\text { Hour }\end{array}$ & $\stackrel{1}{1}$ & $\begin{array}{l}11 / 2 \\
\text { Hours }\end{array}$ & $\stackrel{2}{2}$ & $\begin{array}{l}3 \\
\text { Hours }\end{array}$ & $\begin{array}{l}\text { Aver- } \\
\text { age }\end{array}$ & $\begin{array}{l}\text { Result of } \\
\text { Treatment }\end{array}$ \\
\hline 68 & $F$ & 45 & $21 / 2$ mos. & 0.95 & . & & 2.68 & & 1.11 & 1.89 & No improvement \\
\hline 69 & $\mathbf{M}$ & 35 & 2 yrs. & 0.91 & ..... & $\dddot{2.59}$ & $\ldots .$. & $\ddot{2.1 i}$ & 1.28 & 1.99 & No improvement \\
\hline 0 & $\overline{\mathbf{M}}$ & 31 & 6 mos. & 1.02 & $\ldots$. & 2.35 & $\ldots$ & 2.0 & 1.3 & 1.88 & No improvement \\
\hline 71 & $\mathbf{M}$ & 36 & 6 mos. & 1.3 & .... & 2.7 & .... & 1.7 & 0.7 & 1.7 & Much improved \\
\hline 72 & $\mathbf{M}$ & 52 & 6 mos. & 1.5 & $\ldots$. & 2.5 & & 1.3 & 1.3 & 1. & Much improved \\
\hline 73 & $\mathrm{~F}$ & 37 & 8 yrs. & 1.25 & ..... & & 1.56 & & 1.67 & 1.62 & Much improved \\
\hline 70 & $\mathbf{F}$ & 65 & $1 \mathrm{yr}$. & 1.28 & .... & 2.44 & 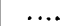 & 1.7 & 1.1 & & Much ir \\
\hline$\pi$ & & 66 & Many & 1.02 & $\cdots$ & 2.06 & $\cdots$ & 1.27 & 1.28 & 1.53 & Much improved \\
\hline 76 & $\mathbf{M}$ & 34 & $\begin{array}{l}\text { years } \\
1 \text { yr. }\end{array}$ & 0.98 & .. & 2.02 & & 2.17 & 1.3 & 1.83 & Improved \\
\hline 77 & $\mathbf{F}$ & 69 & $10 \mathrm{yrs}$. & 1.09 & $\ldots$ & 1.96 & & 1.56 & 1. & 1. & Improved \\
\hline 78 & $\mathbf{F}$ & 53 & $2 \mathrm{yrs}$. & 1.45 & $\ldots$ & & 1.91 & & 1.64 & 1.77 & Improved \\
\hline$=0$ & M & 36 & 6 yrs. & 1.2 & ... & 2.1 & & 2.25 & 0.9 & 1.75 & Much improved \\
\hline 80 & $F$ & 49 & $10 \mathrm{yrs}$. & 1.2 & .... & 2.0 & .... & 1.9 & 0.9 & 1.6 & Improved \\
\hline
\end{tabular}

Cases in which the Average was Over 2 Mg. Per C.c.

\begin{tabular}{|c|c|c|c|c|c|c|c|c|c|c|c|}
\hline 81 & $\mathbf{F}$ & 26 & 7 mos. & 1.29 & 1.78 & 2.72 & $\cdots$ & 2.17 & 1.79 & 2.22 & Recovered \\
\hline 82 & $\mathbf{F}$ & 63 & 16 mos. & 1.02 & 1.90 & 2.42 & $\ldots$ & 2.27 & 1.58 & 2.09 & Much improved \\
\hline 83 & $\overline{\mathbf{F}}$ & 64 & $21 / 2$ yrs. & 1.09 & $\ldots$ & 2.17 & $\ldots$ & 2.53 & 2.15 & 2.28 & Much improved \\
\hline 84 & $\mathbf{F}$ & 22 & 6 wks. & 1.00 & $\ldots$ & 2.60 & $\ldots$ & 2.90 & 2.10 & 2.53 & Much improved \\
\hline 85 & $\mathbf{F}$ & 35 & 4 yrs. & 1.2 & $\ldots$ & 2.4 & $\ldots$ & 2.5 & 1.5 & 2.1 & No improvement \\
\hline 86 & $\mathbf{F}$ & 14 & 2 mos. & 1.1 & $\ldots$ & 2.2 & & 2.3 & 1.5 & 2.0 & Recovered \\
\hline 87 & $\mathbf{F}$ & 55 & $4 \mathrm{yrs}$. & 1.27 & $\cdots$ & & 3.03 & & 3.06 & 3.04 & Improved \\
\hline 88 & $\mathbf{F}$ & 54 & 6 mos. & 2.28 & $\ldots$ & 3.71 & 2.86 & 4.26 & 3.92 & 3.96 & Much improved \\
\hline 89 & $\boldsymbol{F}$ & 52 & $8 \mathrm{mos}$. & 1.78 & $\ldots$ & 3.17 & $\ldots$ & 259 & 1.97 & 2.57 & Recovered \\
\hline 90 & $\mathbf{F}$ & 64 & 6 mos. & 1.5 & $\ldots$ & 3.6 & .... & 3.2 & 2.0 & 2.9 & Much improved \\
\hline 91. & $F$ & & 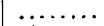 & 1.71 & $\ldots$ & 3.51 & $\ldots$ & 3.64 & 2.51 & 3.22 & Much improved \\
\hline 92 & $\mathbf{F}$ & 52 & 4 yrs. & 1.7 & $\ldots$ & & 4.2 & & 4.1 & 4.1 & Much improved \\
\hline 93 & $\mathbf{F}$ & 61 & 10 yrs. & 1.3 & $\ldots$ & 3.14 & $\cdots$ & 2.68 & 0.86 & 222 & Much improved \\
\hline 94 & $\mathbf{M}$ & 45 & $18 \mathrm{mos}$. & 2.2 & $\ldots$ & 4.5 & $\ldots$ & 4.6 & 3.8 & 4.3 & Much improved \\
\hline 95 & $\mathbf{F}$ & 47 & 5 yrs. & 1.3 & $\ldots$ & 2.6 & $\ldots$ & 3.0 & 1. & 2.5 & Much improved \\
\hline 96 & $\mathbf{F}$ & 32 & 5 yrs. & 1.0 & $\ldots$ & 3.47 & & $\ldots$ & 2.75 & 3.11 & Much improved \\
\hline 97 & $\mathbf{F}$ & 42 & $1 \mathrm{yr}$. & 1.4 & $\cdots$ & $\cdots$ & 2.1 & $\ldots$ & 1.9 & 2.0 & Much improved \\
\hline 98 & $\mathbf{M}$ & 57 & 4 mos. & 1.1 & $\cdots$ & 4.2 & & 1.4 & 0.67 & 2.06 & Much improved \\
\hline 99 & $\mathbf{F}$ & 47 & 4 wks. & $\mathrm{l} .1$ & $\ldots$ & $\because$ & 2.55 & $\ldots$ & 2.0 & 2.24 & Much improved \\
\hline 100 & $\mathbf{F}$ & 27 & $1 \mathrm{yr}$. & 1.34 & $\cdots$ & 3.70 & $\ldots$ & 3.30 & 3.10 & 3.37 & No improvement \\
\hline
\end{tabular}

Group II and four to Group III. It may also be noted that there is no correlation between the figures obtained and the duration of the illness.

A division of the cases according to sex shows that in Group I fifteen are men and nine women; in Group II, twenty are men and thirty-six women; in Group III, two are men and eighteen women. The women, therefore, have a lower tolerance than the men.

An examination of the urine for sugar during the test was done in the earlier cases, but it was found that no glycosuria occurred, even when the blood sugar rose above $1.7 \mathrm{mg}$. per c.c. for a short time, and also the urine would show the absence of sugar throughout the test in cases showing a rise to 1.7 and remaining near this point for three hours. The examination of the urine following administration of sugar could not be used as a substitute for the blood sugar readings, and as it did not provide any additional information bearing on the point in question, the examination was not continued.

The Result of Dietetic Treatment.-The majority of the patients appeared to have received benefit by the treatment described. Of the 
100 patients, eight recovered. These cases were necessarily of less severity than the average and had not gone on to permanent joint change. Forty-three were much improved, twenty-eight were improved and twenty-one showed no improvement. The improvement showed itself: (1) in the objective signs; (2) in relief from the pain and distress suffered by the patient, and (3) in improvement in the general health. In the twenty-eight patients grouped as improved, the result was largely subjective without much objective evidence of change in the joint. The forty-six who were much improved showed change on examination of the joint, as evidenced by decreased swelling, decreased limitation of movement and relief of muscle spasm. In some of these cases the improvement was immediate and striking, and no doubt could be entertained that it was the direct result of dietetic treatment. In two cases, a fall in temperature of 2 degrees (to normal) occurred within forty-eight hours of instituting treatment. As a rule, however, improvement set in slowly, starting in three or four days and being well marked in two or three weeks. After a month of treatment further progress was slow, but it was often marked enough to justify continuance of the diet for many months in favorable cases. Improvement in general health was generally a feature of the progress. Many of the patients suffered especially from some form of chronic dyspepsia, such as eructations of gas, loss or marked increase of appetite and abdominal distress. These symptoms, with very few exceptions, were very much relieved by the dietetic régimen, and sometimes entirely so. Constipation was present in the majority of the cases, often of a very obstinate form, and while at first this symptom might be aggravated somewhat, most patients at the end of their course of treatment would report at least considerable relief from this symptom. Three patients were relieved of chronic eczema. For the first week or two there was almost always some loss of weight. In a patient who was overweight this was desirable, and he was encouraged to reduce his weight further. Underweight was found to be no contraindication to the diet, for after a loss of from 5 to 10 pounds, no further loss was observed and sometimes the loss was followed by a gain to the original weight or even more. Patients who were underweight received as much benefit as did those who were overweight.

As to undesirable results of the treatment, one or two patients were unable to take milk and some other low diet was substituted. One patient had nausea and vomiting. This patient was found to have a heavy indicanuria and after a diet of vegetables, fruit and bread and butter for a week, he was able to continue with the program outlined. No other ill effects were observed as a result of the treatment. 
These results are summarized in Table 2. A separate tabulation of the results with male and female cases shows that females are much more suitable for such treatment than males. The eight patients who recovered were women.

The Relationship of the Sugar Tolerance to the Effect of Reduction in Diet.- In those cases described as improved, the measure of improvement is largely dependent on the statement of the patient and is more or less an uncertain quantity. These cases, therefore, have been considered together with those unimproved for the purpose of demonstrating this relationship. The recovered cases are considered with those much improved, as these cases showed definite objective changes as a result of the treatment. The results are shown in Table 3 .

TABLE 2.-Summary of the Results of Dietetic Treatment

\begin{tabular}{|c|c|c|c|}
\hline & Total & Male & Female \\
\hline 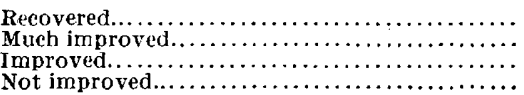 & $\begin{array}{r}8 \\
43 \\
28 \\
21\end{array}$ & $\begin{array}{r}0 \\
14 \\
10 \\
13\end{array}$ & $\begin{array}{r}8 \\
29 \\
18 \\
8\end{array}$ \\
\hline & 100 & 37 & 63 \\
\hline
\end{tabular}

Table 3.-The Effects of Treatment on Cases Grouped According to The Sugar Tolerance

\begin{tabular}{|c|c|c|c|}
\hline \multirow[b]{3}{*}{$\begin{array}{l}\text { Recovery or showing objective improvement....... } \\
\text { No objective improvement......................... }\end{array}$} & \multicolumn{3}{|c|}{$\begin{array}{l}\text { Averaye Blood Sugar Reading } \\
\text { for Three Hours }\end{array}$} \\
\hline & Less than 1.4 & 1.4 to 2 & More than 2 \\
\hline & $\begin{array}{r}3(12.5 \%) \\
21(87.5 \%)\end{array}$ & $\begin{array}{l}31(55.3 \%) \\
25(44.7 \%)\end{array}$ & $\begin{array}{r}17(85 \%) \\
3(15 \%)\end{array}$ \\
\hline
\end{tabular}

TABLE 4.-Analysis of Cases on Basis of SeX.

\begin{tabular}{|c|c|c|c|c|c|c|}
\hline \multirow{3}{*}{$\begin{array}{l}\text { Recovery or showing objective improve- } \\
\text { ment } \ldots \ldots \ldots \ldots \ldots \ldots \ldots \ldots \ldots \ldots \ldots \ldots \ldots\end{array}$} & \multicolumn{2}{|c|}{ Less than 1.4} & \multicolumn{2}{|c|}{1.4 to 2} & \multicolumn{2}{|c|}{ More than 2} \\
\hline & Men & Women & Men & Women & Men & Women \\
\hline & $\underline{0}$ & 3 & 12 & 19 & 2 & 15 \\
\hline No objective improvement.............. & 15 & 6 & 8 & 17 & 0 & 2 \\
\hline
\end{tabular}

Table 4 shows a similar relationship of the results on the sugar tolerance when the male and female cases are separately analyzed.

These figures show that the response to reduction of diet in an arthritic is roughly proportionate to the reduction of the sugar tolerance. This relationship, however, is not without quite evident exceptions. Case 100 , with an average over 3.3 , was a well nourished woman without evidence of any focus of infection which might interfere with progress, yet no effect of any sort was observer as a result of the treatment, and after six weeks she gave it up. In Cases 85 and 87 some relief of symptoms was apparent without any objective change. Both patients, however, were sufficiently impressed with the value of 
the treatment to continue with the diet for several months. One patient (Case 8), who had an almost normal tolerance, showed immediate improvement and has had no relapse after eighteen months. Cases 15 and 24 showed some improvement on examination, but this progress, however, was quite less than the average result. These cases, however, were decidedly the exceptions and it is felt that in a case with a low tolerance one is able to offer, with confidence, a good prospect of improvement; while, on the other hand, a case with normal tolerance seldom showed progress enough to encourage one to recommend this form of treatment as a routine procedure.

\section{DISCUSSION}

Many of the factors exerting an influence on sugar metabolism are still somewhat obscure, and the clinical significance of the glucose tolerance test is as yet uncertain. The test was originally introduced with the object of detecting the potential diabetic but the occurrence of a low tolerance in other conditions has rendered its use for this purpose somewhat unreliable when considered by itself. A low tolerance has also been accepted as evidence of some endocrine unbalance but its value here is as yet unproved. There is some evidence to suggest that a disturbance of the sugar tolerance is associated with infections, as suggested by Pemberton and Foster ${ }^{2}$ and also by the studies of F. M. Allen ${ }^{6}$ and others on diabetics. Our own experience would bear this out. In one case a slightly lowered tolerance was converted into a very much lowered tolerance by the operation of tonsillectomy, and for three weeks the blood sugar remained above 3 for the three hours of the tolerance test. After four weeks the tolerance test returned to the original reaction. It is our opinion that this temporary disturbance of sugar tolerance was due to a lighting up of the infection at the site of the operation. As a general rule, the tolerance is increased by removal of foci of infection. It is reasonable then, to account for the lowering of tolerance in arthritis by the presence of an infection, and Pemberton suggests that the rationale of his dietetic treatment is that he is catering to a function weakened by infection. But, on the face of it, it is difficult to believe that in some of the milder causes of Group III such a disturbance in sugar metabolism could be brought about by the arthritic infection alone.

If the lowering of the tolerance is not the result of the disease process, it is quite possible that it is associated with the pathogenesis of arthritis. Clinical observation would seem to offer some support of this hypothesis. In one case we were able to produce an acute exacerbation of the disease by allowing carbohydrates freely; this was

6. Allen, F. M.: Unpublished Studies on Diabetes quoted by Sherrill, J. W., J. A. M. A. 77:23 (Dec. 3) 1921. 
done three times in the same case. Pemberton brought about a similar relapse in one of his cases in the same way. When the former diet of the patients is scrutinized, it is often found to have been unbalanced, especially in excess of carbohydrate food, and the frequency of this observation is such as to suggest that it should be considered as a possible cause of the condition. And, lastly, the results of treatment in the present series of cases would appear to have an important bearing on this point. No explanation is sufficient which suggests that the treatment is directed simply toward the relief of some secondary process, for sometimes the response is so marked and so striking that one is convinced that the diet must be closely related to the origin of the disease, and the relationship of the sugar tolerance to these results would indicate that this origin is intimately connected in some way with the metabolism of carbohydrates.

Further discussion of this subject may be speculative, but, perhaps, one or two more points may be brought up. When various low diets were being tried, it was found that reduction of carbohydrates alone did not yield the best results, and the diet finally chosen was one which was not only low in calories but which was rich in vitamin content. Results with this diet appeared to be favorable enough to suggest the existense of an actual vitamin deficiency. Others, notably Thompson, ${ }^{7}$ have emphasized the importance of these accessory food factors in the diet of arthritics. The addition, however, to the patient's former diet of food rich in vitamin was by no means as effective as the combination of vitamins with a subcaloric diet, as described, and if a vitamin deficiency exists in those cases which received benefit by reduction of carbohydrates, it is likely that carbohydrates play some part in the production of this deficiency. McCarrison ${ }^{8}$ and Mellanby ${ }^{9}$ have found that carbohydrate excess is an important factor in deficiency disease, and Funk ${ }^{10}$ associates vitamin $B$ with carbohydrate metabolismreporting a hyperglycemia in beriberi. Findlay, Paton and Sharpe ${ }^{11}$ found a decreased sugar tolerance in a case of rickets. McCarrison further believes that excess of fats as well as carbohydrates must be considered in the production of deficiency disease. This fits in well with our own observations on the dietetic treatment of the arthritics who were overweight. For in these cases, reduction of fat has always appeared beneficial, and, while reduction of fat has not been urged in

7. Thompson, F. G.: Dietetics in Chronic Arthritis, Practitioner 103:110 (Aug.) 1919.

8. McCarrison, R.: Studies in Deficiency Disease, London, 1921.

9. Mellanlby, E.: Accessory Food Factors in Feeding of Infants, Lancet 1:856 (April 17) 1920.

10. Funk, C.: Action of Substances Influencing Carbohydrate Metabolism in Experimental Beri Beri, J. Phyiol. 53 :247 (Dec.) 1919.

11. Findlay, L., Paton, D. N., and Sharpe, J. S.: Studies in Metabolism of Rickets, Quart. J. Med. 14:352 (July) 1921. 
those underweight, it has been given in the form of cod liver oil and cream in moderation. Such a deficiency would also account for the relationship of diet with what appears to be a infectious disease, for it has been repeatedly found, as pointed out by McCarrison ${ }^{8}$ and Hess ${ }^{12}$ that infections readily light up in deficiently fed animals.

If, then, excess of the energy bearing constitutents of the food may induce deficiency disease, especially in the presence of inadequate vitamins and protein, and if infections are liable to appear before actual deficiency syndromes develop, it is a fair hypothesis that in the presence of some focus of infection lack of balance in the diet is a cause of chronic arthritis in a large number of cases, and that the results reported in this paper are due to measures directed toward the correction of this defect.

These considerations are presented with the full appreciation of the fact that one phase only of the treatment has been dealt with. If diet is a factor in the etiology of this disease, there are likely many others, as, foci of infection, exposure, fatigue and other disease. Influenza was the exciting cause in many of the cases studied, and these cases were sometimes among those most favorably influenced by diet. It is interesting to note that a low sugar tolerance may follow this disease (Cowie and Beavan ${ }^{13}$ ).

No special observations are included as to the value of other therapy for the object of the investigation was to study the value of diet alone, but after this had been observed, it was found worth while to institute other forms of treatment, especially hydrotherapy and physiotherapy. Foci of infection, when of considerable size, appeared to interfere with the favorable effects of diet, and it is recommended that these should always be looked for and, if possible, removed before dietetic treatment is started. One patient, however, recovered in spite of the existence of several abscesses at the roots of the teeth, which the patient had refused to have extracted. But such infectious foci were found only in a minority of the cases, and when removed none of the effects reported here could be attributed to this procedure.

The more favorable results, along with the considerably lower tolerance in women, might call for some comment. This might be associated with some fundamental difference in their metabolism, to their manner of living, or, perhaps, to their dietetic habits. Certainly, lack of balance in diet is more frequently found among women than among men, especially carbohydrate excess, with an inadequacy of protein. In this connection, it might be mentioned that reduction of protein in chronic arthritis, as is so often practised, appears to be productive of much harm.

12. Hess, A. F.: Newer Aspects of Some Nutritional Disorders, J. A. M. A. 76:693 (March 12) 1921.

13. Cowie, D. M., and Beavan, P. W.: Arch. Int. Med. 24:78 (July) 1919. 


\section{CONCLUSIONS}

1. Of 100 cases of chronic arthritis, reduction of diet alone appeared to result in the recovery of eight patients and in quite evident improvement in forty-three.

2. The sugar tolerance was decreased in the large majority of these cases, and this decrease showed no relationship to the severity of the disease.

3. Patients who have a low tolerance are much more frequently benefited by reduction in diet than those cases with a normal tolerance.

4. In certain cases of chronic arthritis, dietetic regulation appears to be the most effective form of treatment, and while the value of such treatment in an individual case cannot be determined with certainty, the lowering of the sugar tolerance is a useful clinical indication for this procedure.

5. Female patients derive greater benefit from such treatment than men, and, as a rule, they show a lower tolerance. 